التشـابه والإختلاف في الأصهوات باللغة العربية والجاوية (الدراسة التقابلية في اللغة العربية

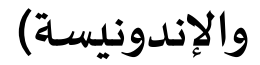
سارة موتييارا، عزيزريطنجا، إيمزير خريجة قسم التربية اللغة العربية - جامعة جاكرتا الحكومية لمرية

\title{
البريد: sarah.fatimah@unj.ac.id
}

\section{التجريد}

يهدف هذا البحث لمعرفة التشاباه والاختلاف في الأصوات باللغة العربية والجاوية. البحث يستخدم طريقة التقابل اللغوي مع أسـاليب البيانات الاولية و البيانات الثانوية. هناك بعض التشابهات في الصيوت بالعربية والجاوية. اللغة العربية واللغة الجاوية لديها بعض التشابة من الأصوات الصائتة. وبين اللغتين أيضا بعض من نفس الأصيوات الصامتاة. هناك بعض اختلافات في الصوت باللغة العربية والجاوية. اللغة العربية واللغة الجاوية لديها بعض المختلفة من الأصهوات الصائتة. وبين اللغتين أيضا بعض اختلافات من الأصيوات الصامتاة. واللغة العربية لديها أنصاف الحركات، وفي مني حين ان اللغة الجاوية ليست لديها أنصاف الحركات. بعض الاختلافات والتشابهات بين اللغتين

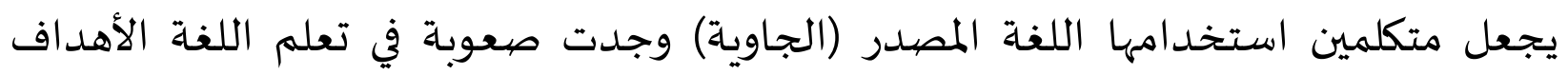
واستخدام العربية. ولذلك هناك التنبؤ بالأخطاء والصعوبات للمتكلمين. الطريقة في التنبؤ بالصعوبات هي مقارنة الأصوات اللغتين. الكلمة المفتاحية: التشابه، الاختلاف، الأصهوات 


\begin{abstract}
ABSTRAK
Penelitian ini bertujuan untuk mengetahui persamaan dan perbedaan bunyi dalam Bahasa Arab dan Bahasa Jawa. Penelitian ini menggunakan metode analisis kontrastif dengan teknik pengumpulan data melalui data primer dan data sekunder. Penelitian ini dilakukan di Universitas Negeri Jakarta - Jakarta Timur, pada bulan September 2017 sampai Januari 2018.

Hasil penelitian menunjukkan bahwa terdapat perbedaan dalam bunyi Bahasa Arab dan Bahasa Jawa. Penelitian juga menunjukkan bahwa terdapat persamaan dalam bunyi Bahasa Arab dan Bahasa Jawa. Terdapat beberapa persamaan bunyi dalam Bahasa Arab dan Bahasa Jawa. Bahasa Arab dan Bahasa Jawa memiliki beberapa fonem vokal yang sama. Kedua bahasa tersebut juga memiliki beberapa fonem konsonan yang sama. Terdapat beberapa perbedaan bunyi dalam Bahasa Arab dan Bahasa Jawa. Bahasa Arab dan Bahasa Jawa memiliki beberapa fonem vokal yang berbeda. Kedua bahasa tersebut juga memiliki beberapa fonem konsonan yang berbeda. Selain itu, Bahasa Arab memiliki semivokal, sedangkan Bahasa Jawa tidak memiliki semivokal. Selain mengalami kesulitan, perbedaan dan persamaan dalam Bahasa Arab dan Bahasa Jawa juga dapat menyebabkan timbulnya interferensi bahasa. Hal ini dapat disebabkan oleh penutur bahasa sumber (Bahasa Jawa) yang sudah terbiasa menggunakan bahasanya, sehingga kebiasaan tersebut digunakan dalam mempelajari bahasa tujuan (Bahasa Arab). Dengan demikian, terjadilah pencampuran dua kaidah bahasa yang seharusnya tidak boleh dilakukan karena setiap bahasa memiliki kaidah bahasa yang berbeda dengan bahasa yang lainnya.
\end{abstract}

Kata kunci: Persamaan, Perbedaan, Bunyi

مقدمة

تظهر النتائج أن هناك فرقا في أصوات اللغة العربية واللغة الجاوية. وتبين البحوث أيضا

ان هناك تشابة في الأصيوات اللغة العربية واللغة الجاوية.

هناك بعض التشابهات في الصوت بالعربية والجاوية. اللغة العربية واللغة الجاوية لديها

بعض التشابة من الأصيوات الصائتة. وبين اللغتين أيضا بعض من نفس الأصيوات الصامتة. 
هناك بعض اختلافات في الصوت باللغة العربية والجاوية. اللغة العربية واللغة الجاوية لديها بعض المختلفة من الأصيوات الصائتة. وبين اللغتين أيضا بعض اختلافات من الأصهوات الصامتة. واللغة العربية لديها أنصاف الحركات، وفي حين ان اللغة الجاوية ليست لديها أنصاف الحركات.

بعض الاختلافات والتشــابهات بين اللغتين يجعل متكلمين اسـتخدـامها اللغة المصــدر (الجاوية) وجـدت صـــوبـة في تعلم اللغــة الأهـداف واســتخـدام العربيـة. ولـذلك هنـاك التنبؤ بـالأخطاء والصــعوبات للمتكلمين. الطريقة في التنبؤ بالصـــوبات هي مقارنة الأصـــوات اللغتين. و تركيز البحث هو المقارنة بين الأصهوات العربية والأصيوات الجاوية (الدراسـة التقابلة)

مكان البحوث التي أجريت في جامعة جاكرتا الحكومية. وأما وقت البحوث فهي: من سبتمبر

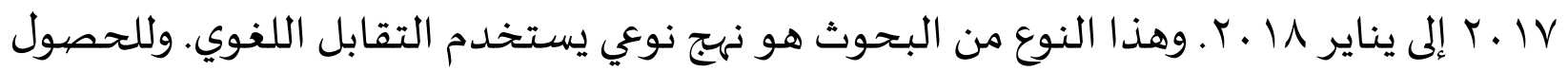
علي الحد الأقصى من البيانات ، يقوم الباحثة أيضا باجراء مكتبة بحوث (بحوث المكتبة) ، وان معظم الانشطة البحثية المضطلع بها في المكتبة. هذا البحث هو أيضا دراسـة للمكتبة بحيث يتطلب الكثير من المعلومات من البحوث السابقة. 


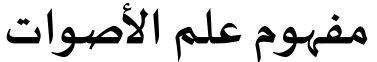

علم الأصوات في اللغة العربية ووصف علم الأصهوات, وعلم الأصيوات هو العلم ان الدراسات حول لغتها السليمة من الكلام ، والتشريد ، والقبول. هذا العلم لا يزال شائعا ، وتشمل طبيعة المادياة ، والسمعية ، أو المختبر ؛ وهذا أمر عام أو خاص ؛ هذه هي النظرية أو الممارسة ؛ تحتوي علي المعني ام لا. ( محمد علي الخول، 1982 : 112). مفهومة التقابل اللغوي من الناحية المنهجية ، كلمة تقابل تاتي من الكلمة contrastive الكلمات المشتقة من الأفعال to contrus المعنى يعني مختلفة ومتناقضة. . John M. Echols dan Hasan Sadily, ( 1998 : 144 وفي حين انه وفقا للمصطلح هناك عدة اراء وفقا للخبراء ، وهي : (Henry Guntur Tarigan) هنري غنتور تارغان)

التقابل اللغوي هو إجراءات العمل ، أو الانشطة التي تحاول مقارنة هيكل اللغة الام والصيغة المستهدفة (B1) لتحديد الاختلافات بين اللغتين. يمكن استخدام الفرق في اللغتين التي يتم إنشاؤها من خلال تحليل كونترواسيف ، كاساس في التنبؤ أو التنبؤ بصعوبات تعلم اللغة التي سيواجهها الطلاب في المدرسة ، وخاصة عند تعلم اللغة المستهدفة . ( Henry Guntur Tarigan, 2009: 23 
ALMAKRIFAH, Vol.14 (1) April 2017

وفيما يلي هذه نتائج البحوث التي قام به اللباحثة عن المقارنة بين أصوات اللغة العربية و

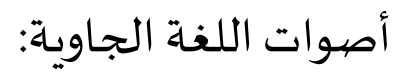

أ. المعادلة من أصهوات اللغة العربية واللغة الجاوية

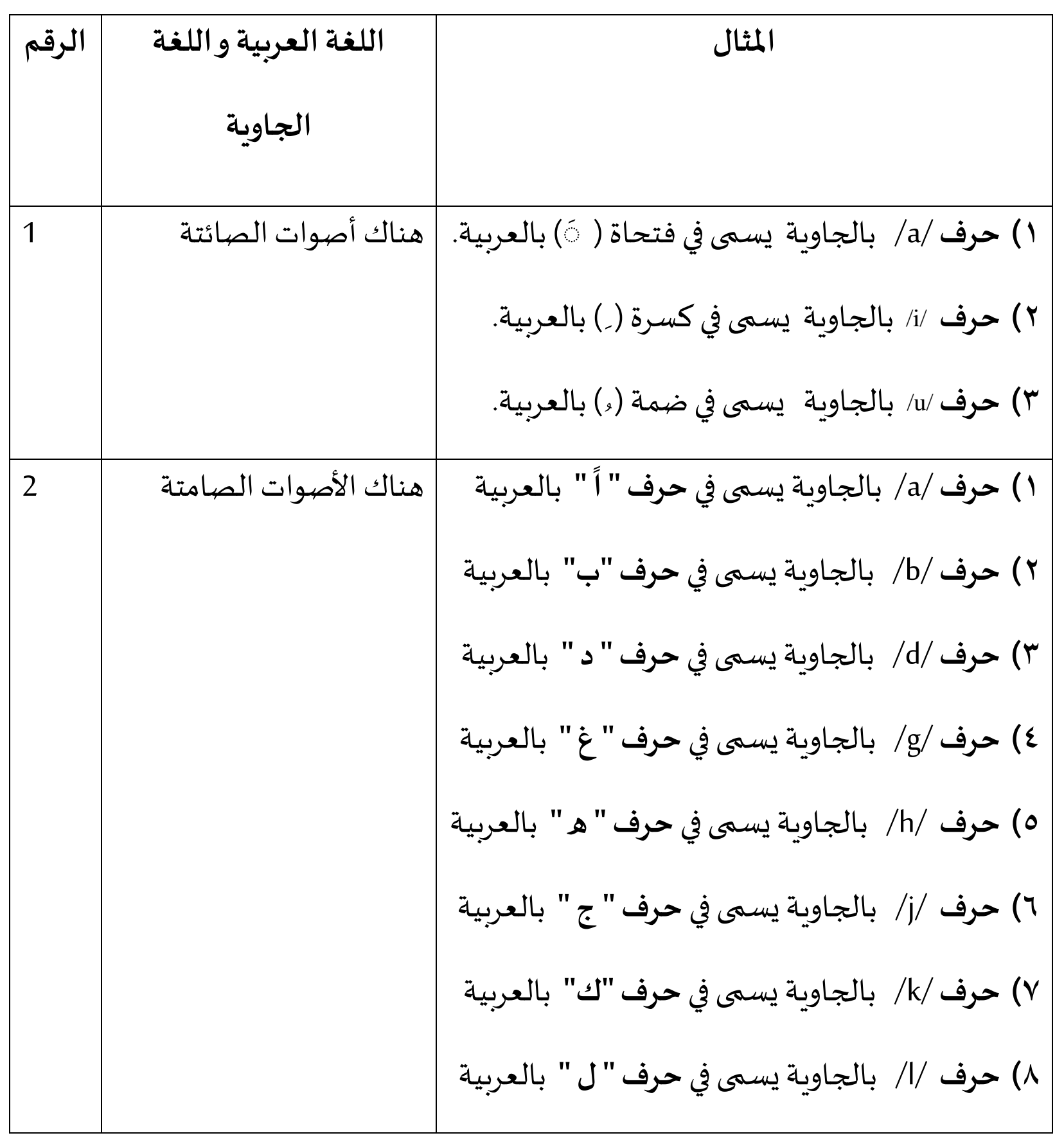

96 
ALMAKRIFAH, Vol.14 (1) April 2017

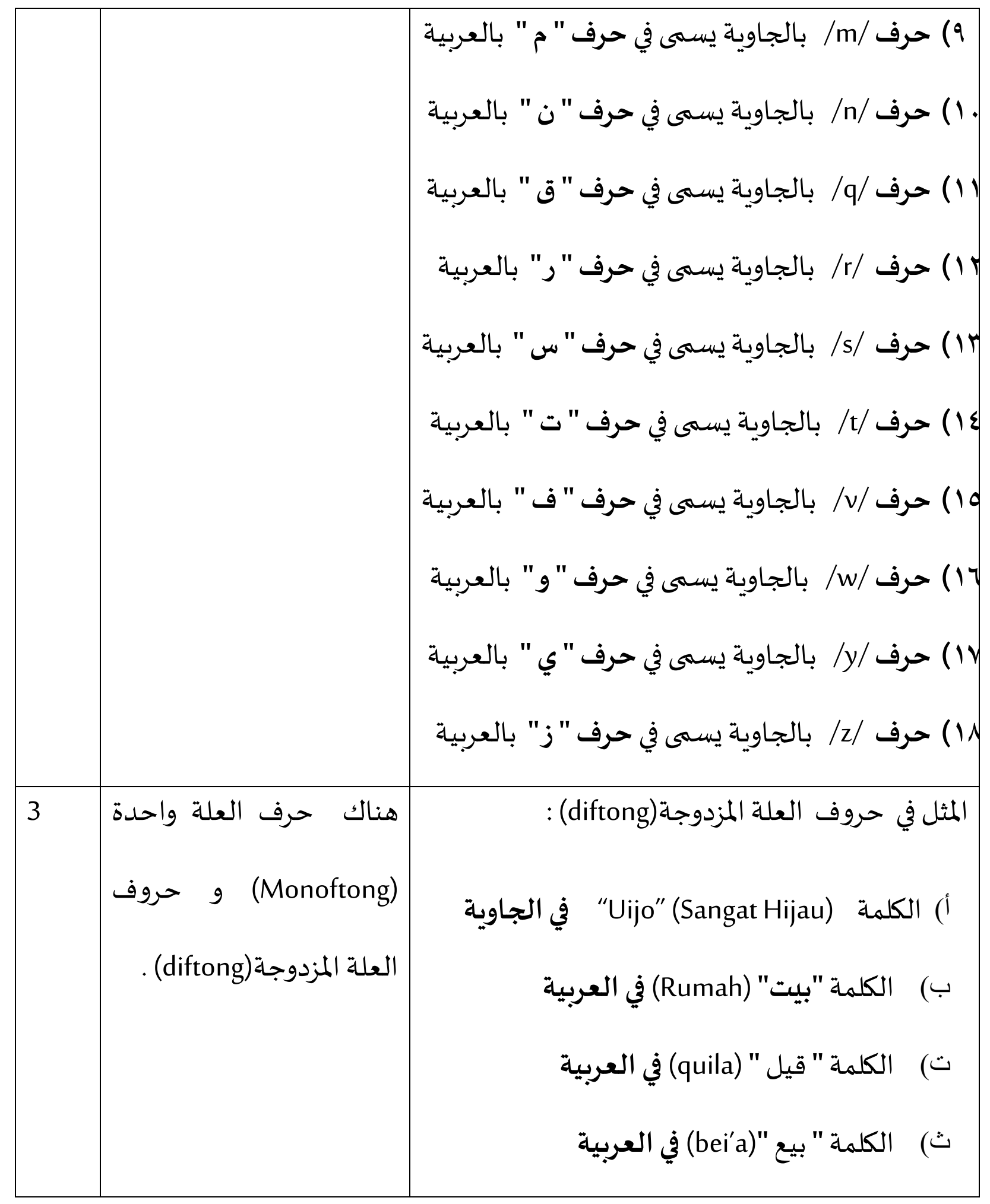

97 


\section{ب. الفرق من أصوات اللغة العربية واللغة الجاوية}




\begin{tabular}{|c|c|c|}
\hline الرقم & اللغة العربية & اللغة الجاويـة \\
\hline 1 & 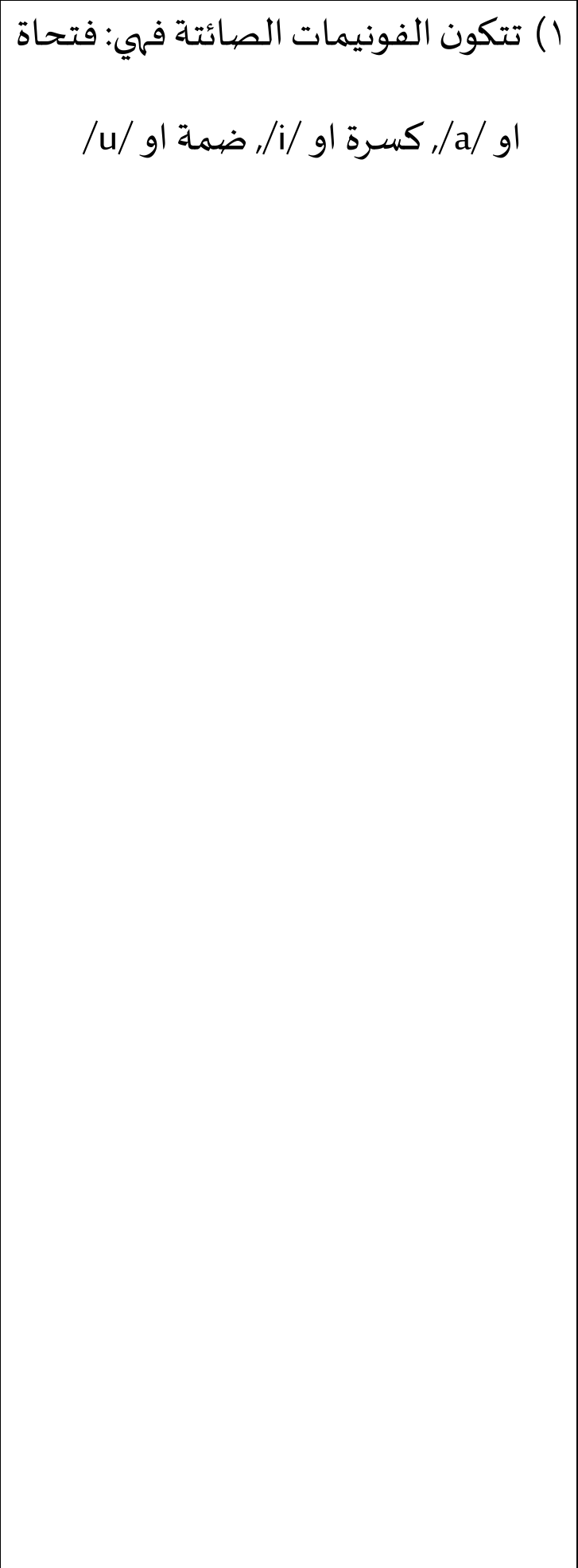 & 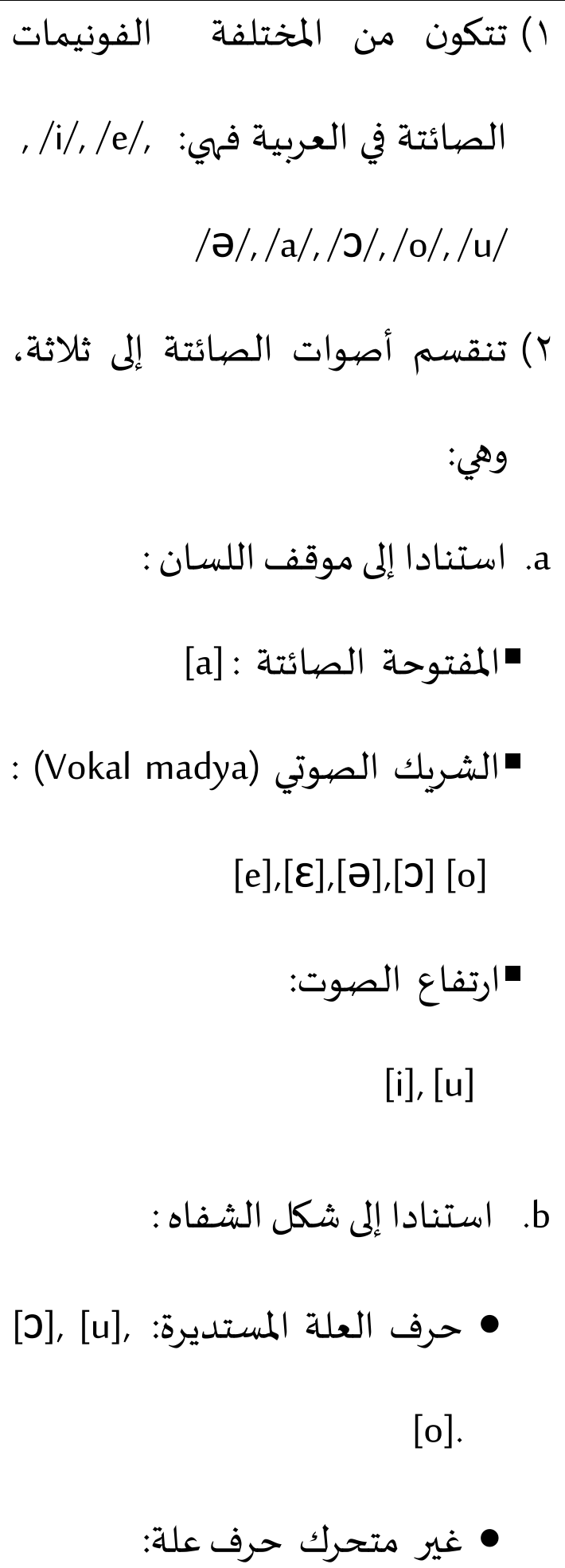 \\
\hline
\end{tabular}




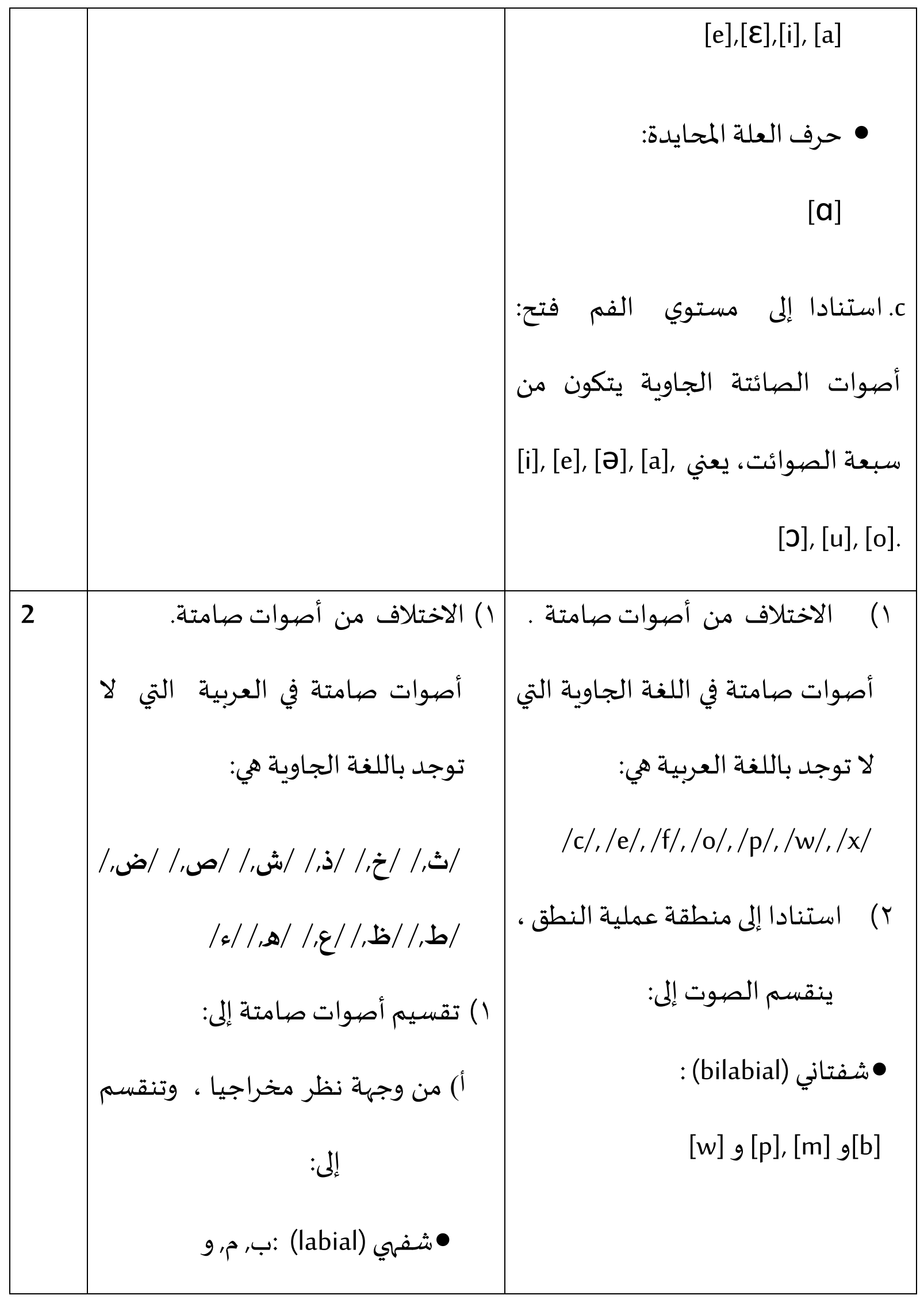




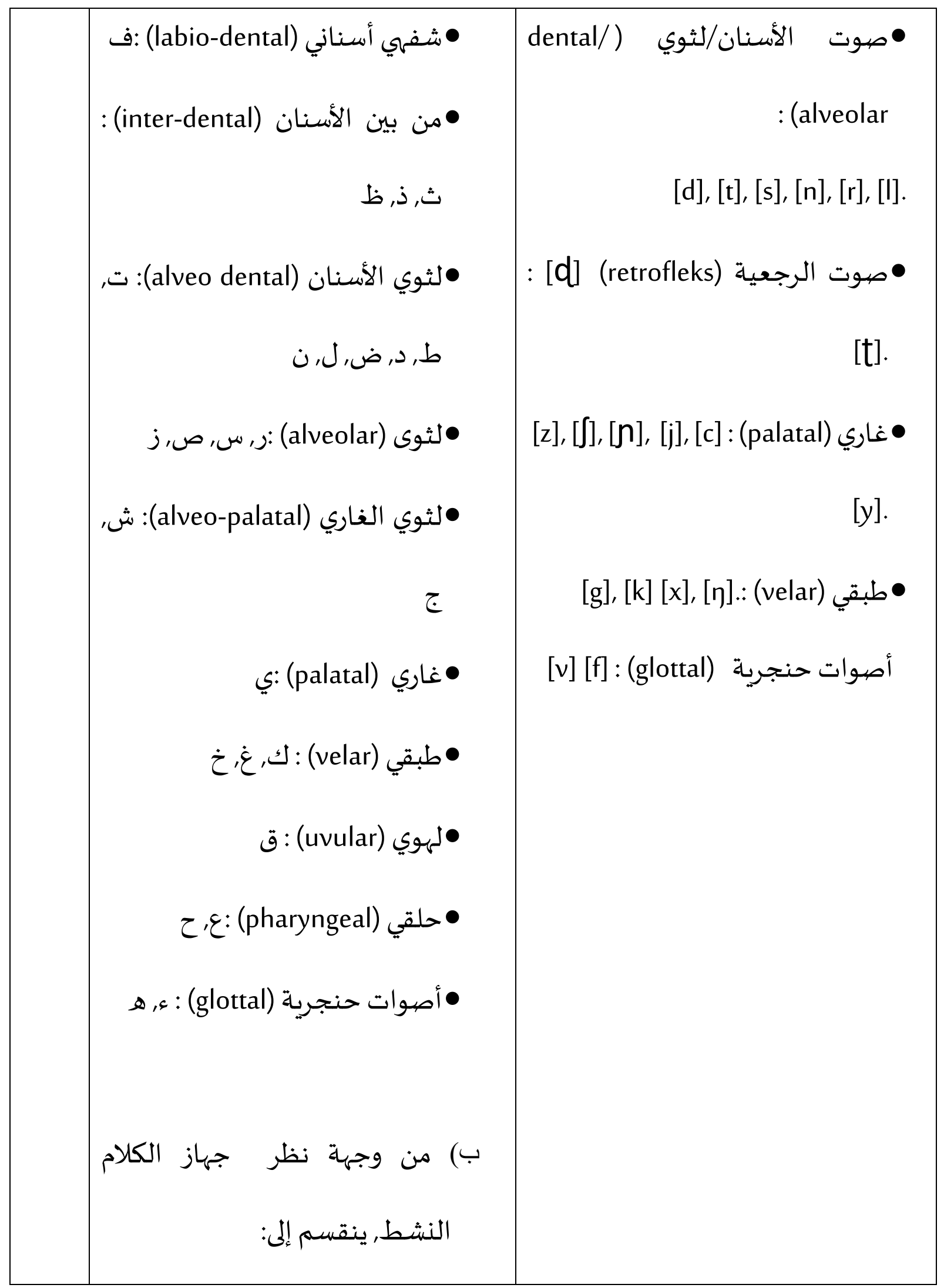




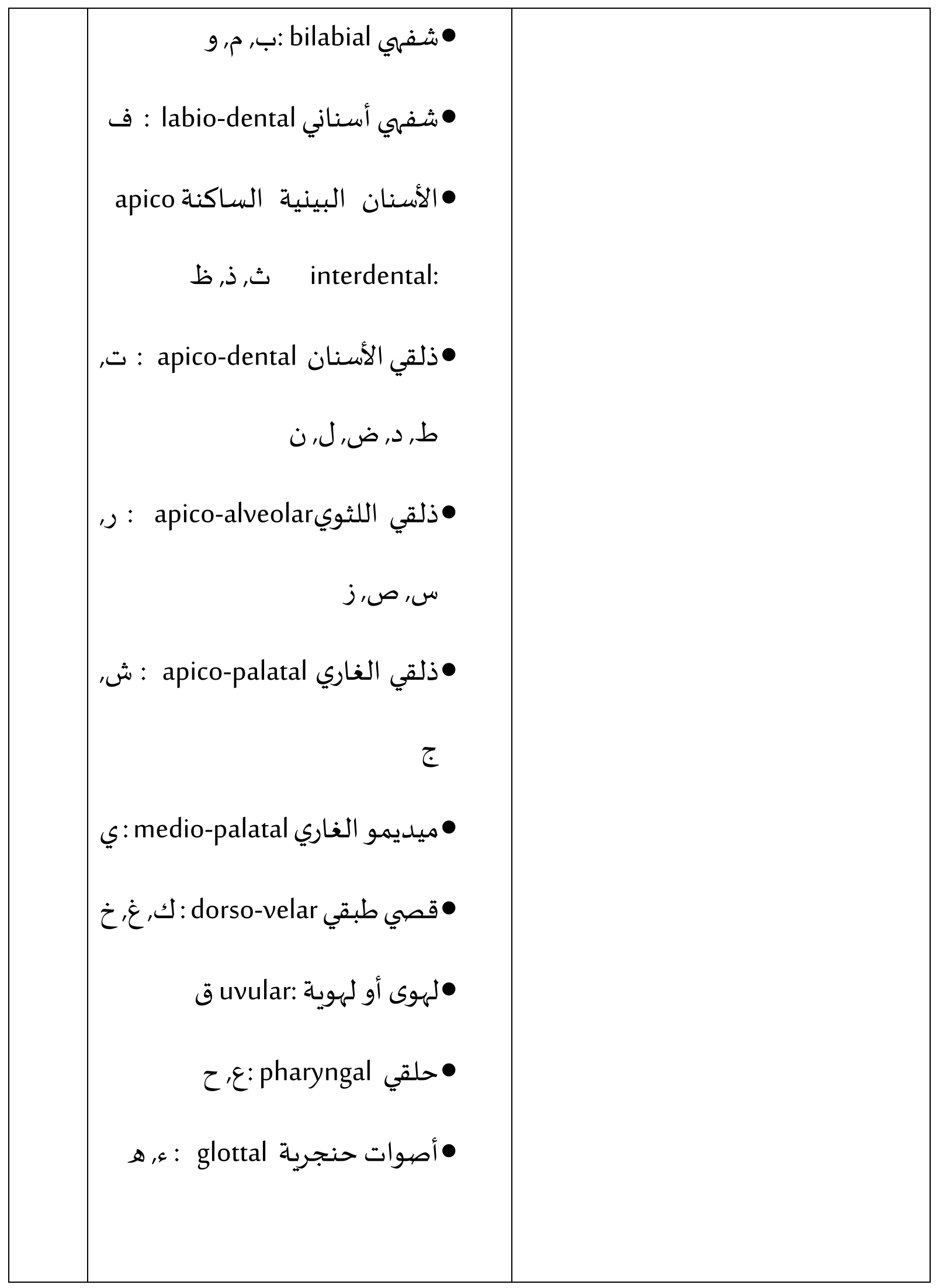




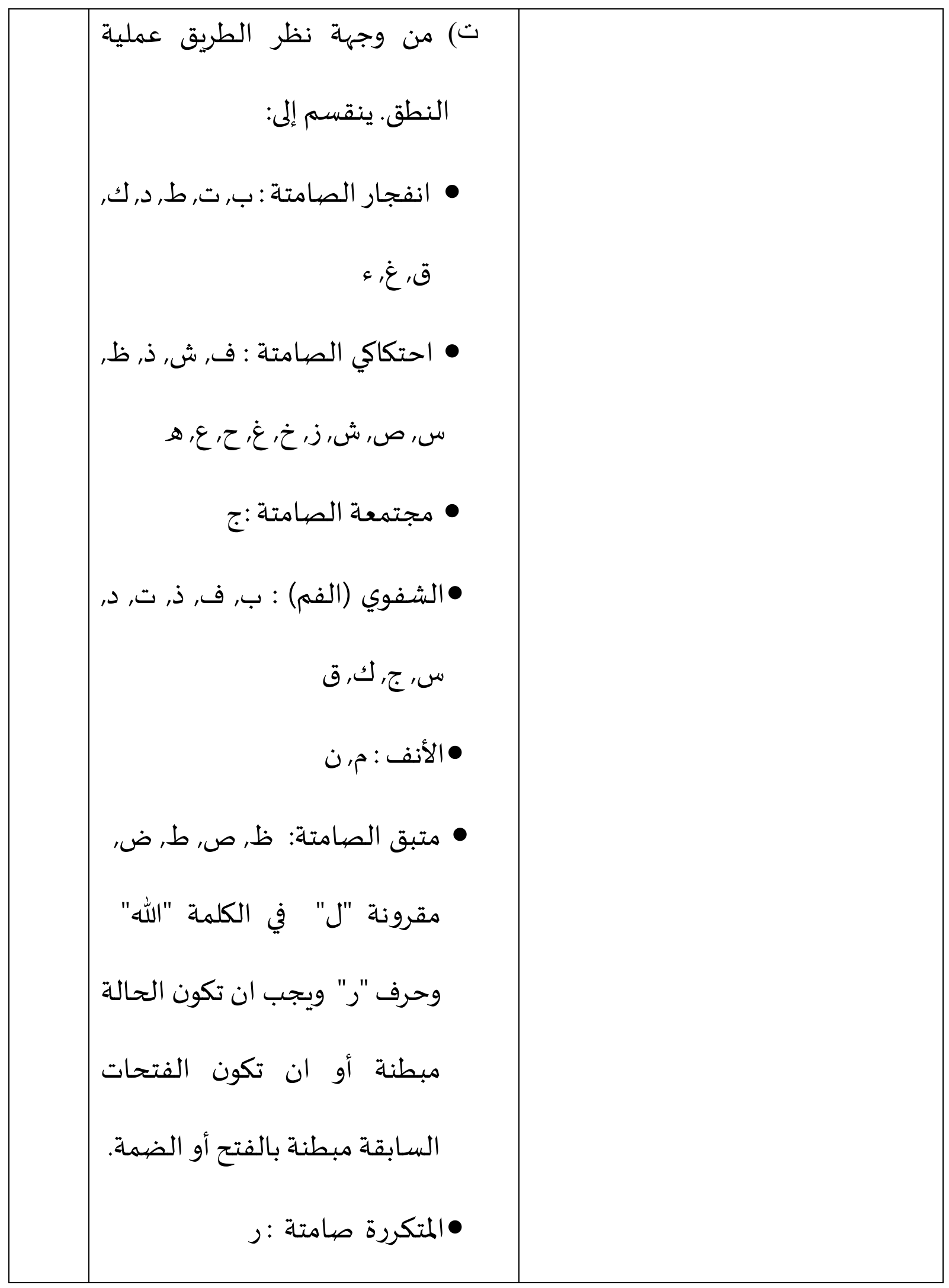




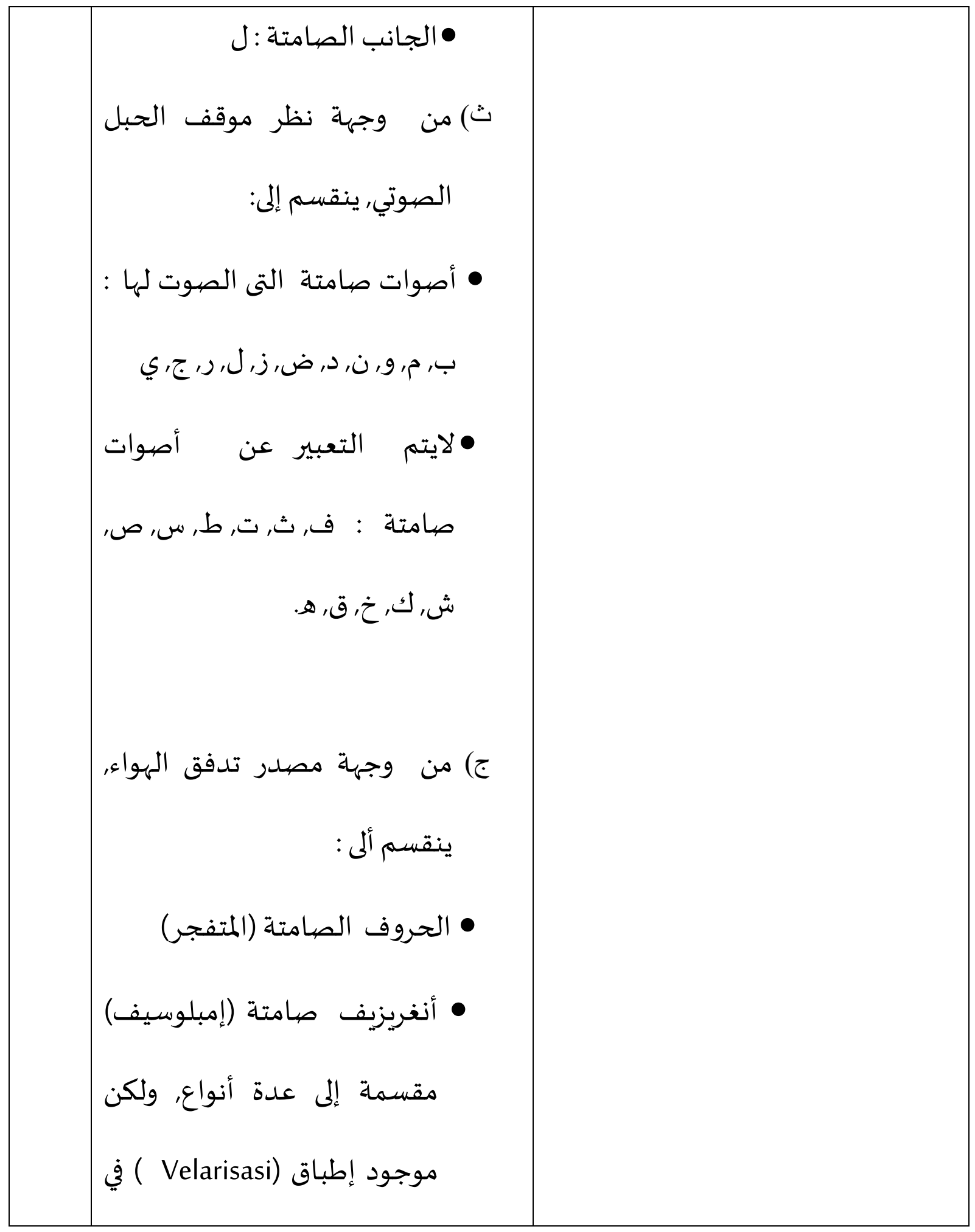




\begin{tabular}{|c|c|c|}
\hline & : أصوات الصامتة في اللغة العربية & \\
\hline r & هناك أنصاف الحركات & لا يوجد أنصـاف الحركات \\
\hline
\end{tabular}

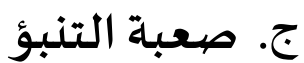

استنادا إلى الجدول أعلاة, فإن التنبؤبالصعبة هو :

( ) المتكلمين الجاوية لديهم صعبة في أنصاف الحركات بالعربية ، لأنه لا توجد أنصاف

$$
\text { الحركات في الجاوياة. }
$$

r) هناك حروف العربية التي يصعب لنطقها لأها ليست بالجاوية ، مثل:ع, غ, خ, ح, ث,

$$
\text { ذ, ز, ش, ط, ظ, ص, ض, ق }
$$

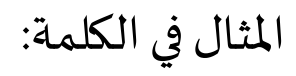

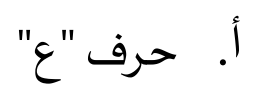

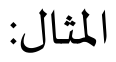

• الأسم "سعيد" تغير إلى "Sangit" في اللغة الجاوية.

• الأسم "سعيد" تغير إلى "A id” في اللغة الجاوية. 


$$
\text { المخرج لحرف "ع" هوفي الحنجرة }
$$

$$
\text { ب. حرف "غ" }
$$

• الأسم "غائب" تغير إلى "ga ib" في اللغة الجاوية.

$$
\text { • المخرج "ينبغي" تغير إلى "yanbagi" في اللغة الجاوية. }
$$

$$
\text { ت. حرف "خ" }
$$

\section{• الأسم "خاتمة" تغير إلى "hatimah" في اللغة الجاوية. \\ ه الأسم "خارج" تغير إلى "harij" في اللغة الجاوية.

$$
\text { المخرج لحرف "خ" هوفي طبقي }
$$

$$
\begin{aligned}
& \text { ث. حرف "ح" } \\
& \text { المثال: }
\end{aligned}
$$

\footnotetext{
• الأسم "حسن" تغير إلى ”Kasan" في اللغة الجاوية.
} 
• الأسم "حسين" تغير إلى " Kusein" في اللغة الجاوية. المخرج لحرف "ح" هو في الحنجرة

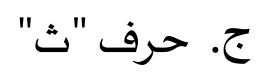

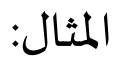

• الأسم "ثابتة" تغير إلى "Sabitah" في اللغة الجاوية. • الأسم "حادثة" تغير إلى "hadisah" في اللغة الجاوية. التعاون من الأسنان الوسطي مع غيض من الصيوت إنتاج اللسان " ث"

$$
\text { ح. حرف "ذ" }
$$

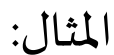

• الأسم "ذاكرة" تغير إلى "jakirah" في اللغة الجاوية.

$$
\text { • الأسم "ذائب" تغير إلى "ja ib" في اللغة الجاوية. }
$$

عندما ذلق اللسـان إجتمع بدلف الأسـنان والتعاون من الأسـنان الوسطي مع

$$
\text { غيض من الصوت هناك الصوت "ذ" المثال: }
$$


• الأسم "زائد" تغير إلى ”ja id في اللغة الجاوية.

• الأسم "زائغ" تغير إلى "ja ig في اللغة الجاوية.

$$
\text { المخرج لحرف "ز" هو في لثوي }
$$

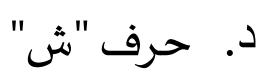

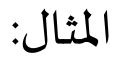

• الأسم "شاب" تغير إلى "Sab" في اللغة الجاوية.

$$
\text { • الأسم "شارع" تغير إلى "Sari' في اللغة الجاوية. }
$$

عندما ذلق اللسان إجتمع بالحنك الصلب هناك الصوت "ش"

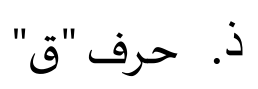

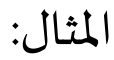

• الأسم "قائد" تغير إلى ”ka id" في اللغة الجاوية.

$$
\text { • الأسم "قابل" تغير إلى "kabil" في اللغة الجاوية. }
$$

التعاون بين لسان الطفل ولسانه ينتج بنغال مخرج الصوت "ق". 


$$
\begin{aligned}
& \text { ر. حرف "ط" } \\
& \text { المثال: } \\
& \text { • الأسم "طائر" تغير إلى "ta ir" في اللغة الجاوية. } \\
& \text { الأسم "طابق" تغير إلى "tabik" في اللغة الجاوية. } \\
& \text { التعاون علي قاعدة الأسنان مع غيض من الصوت إنتاج الصوت "ط" } \\
& \text { ز. ـرف "ظ" } \\
& \text { المثال: } \\
& \text { • الأسم "ظرف" تغير إلى "jarf" في اللغة الجاوية. } \\
& \text { • الأسم "ظاهر" تغير إلى "jahir" في اللغة الجاوية. } \\
& \text { عندما ذلق اللسـان إجتمع بدلف الأسنان هناك الصيوت "ظ" }
\end{aligned}
$$

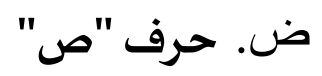

$$
\begin{aligned}
& \text { المثال: } \\
& \text { • الأسم "صائن" تغير إلى "sa in" في اللغة الجاوية. } \\
& \text { • الأسم "صاح" تغير إلى "sah" في اللغة الجاوية. }
\end{aligned}
$$




\section{المخرج لحرف "ص" هو في لثوي}

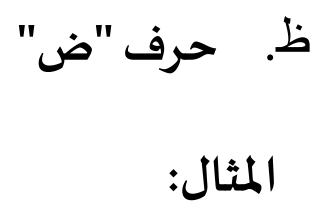

• الأسم "ضياحكا" تغير إلى "dahikan" في اللغة الجاوية.

• الأسم "ضارية" تغير إلى "dariyah" في اللغة الجاوية.

عندما يتم الوفاء حافه اللسان و التعاون علي قاعدة الأسنان مع غيض من

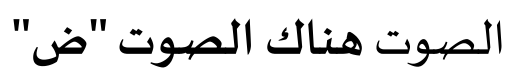

r) المتكلمون لديهم صعوبة في التمييز بين طريقة نطق عدة أحرف العربية ، بما فياه

$$
\text { المندال في الكلماة: }
$$

نطق "الفرق" التي ينبغي قراءها باستخدام الحرف "ق" في اللغة العبية تغير إلى

"Al-Fark" في اللغة الجاوياة, وعندما ينبغي قراءتها "K" لذلك يقرأ في "Al-Farq".

• نطق "صغر" التي ينبغي قراءتها باستخدام الحرف "ص" في اللغة العربية تغير إلى

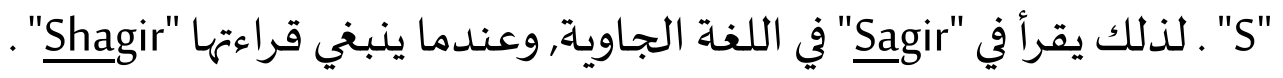


نطق "خائف" التي ينبغي قراءها باستخدام الحرف "خ" في اللغة العربية تغير إلى لذلك يقرأ في "Haif" في اللغة الجاوية, وعندما ينبغني قراءها "Khaif". • المتكلمين اللغة الجاوية لاتزال صعبة للتمييز بين طريقة النطق على الحروف "ع" و "أ". وبااتالي فإن نفس الطريقة من النطق. المثال: الكلمة "عائلة" التي ينبغي قراءتها باستخدام الحرف "ع" في اللغة العربية تغير إلى "A" , لذلك يقرأ في "A "ilah

غ. امكانية التدخل اللغوي

يمكن ان يحدث التدخل اللغوي من دراسـة الأصهوات للغة المصدر (الجاوي) ولغة الوجهة

$$
\text { (العربية). والسبب هو : (السب }
$$

( ) هنالك الفرق بين اللغتين لذلك المتكلمين الجاوية لديهم مشكلة في الدراسة اللغة العربية r) اعتادوا على استخدام اللغة المصدر (جاوي) لذلك تتم هذه العادة عند تكلم وتعلم لغة

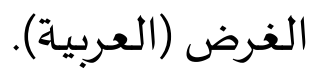

r) حب المتكلمين لقبيلة لهم (جاوي) لذلك المتكلمين يريدون استعمال على استخدام قواعد

$$
\text { والعادات من لغة المصدر (جاوي) عند تكلم وتعلم لغة الغرض (العربية). }
$$

استنادا إلى نتائج البحوث التي قامت بها الباحثة بين أصوات اللغة العربية واللغة الجاوية ،

$$
\text { يمكن ان يحدث التدخل عندما: }
$$


1) نطق بعض الأصوات الصائتة باللغة الجاوياة ، ولكن لا يوجد شيء في اللغة العربية ، مثل : / / / / / ـ فانه قد يسبب المتكلمين خلط ضجة بين اللغتين

r) أصهوات الصائتة الجاوية هناك باللغة العربية ، ولكن يتم تقسيم الحروف إلى عدة أنواع ، مثل: أ. أحرف العلة /i / التي تنقسم إلى: " I jejeg و" و "

ب. أحرف العلة /e / التي تنقسم إلى: " e swara jejeg" و" e swara miring " ج.أحرف العلة /u/ التي تنقسم إلى:" u swara jejeg" و" u swara miring " فانه قد يسبب المتكلمين خلط ضجة بين اللغتين r) الأصيوات الصامتاة يمكن ان يكون الفرق قد يسبب خلط ضجة بين اللغتين لان المتكلمين الجاوية اعتاد على ذلك مع أصوات الصامتة الجاوية ، ولكن غير مالوفة مع أصوات الصامتا العربية. مثل: نطق حرف "ع" يصبح "a".

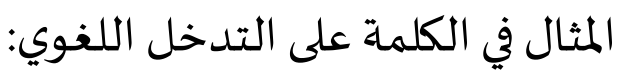

الكلمة "باب" (babun) نطق الحرف /b / من الكلمة "babun" باستخدام لهجة الجاوية مع

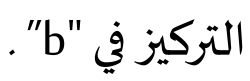

النطق "الحمد الله الر بالعالمين" (Alhamdulillahirrobil ’alamin) ) تغير إلى "Alhamdulillahirrobil ngalamin" 


$$
\text { ه. الحلول من الخطأ على أصيوات اللغة }
$$$$
\text { غالبا ما يستمع إلى المحادثات اليومية باللغة العربية }
$$

من خلال الاستماع في كثير من المحادثات العربية, وسوف تعتاد المتكلمين في سماع الحروف

$$
\text { غالبا ما يمارس التحدبية. ولذلك سوف يكون المتحدثون تعتاد على الأصهوات العربية. }
$$

يحتاج المتحدثون إلى ممارسة التحدث باللغة العربية. يمكن للمتكلمين على ممارسـة قراءة النص العربي أو الحوار باستخدام اللغة العبية. ولذلك سوف تعتاد أجهزة الكلام المتكلمين في نطق الحروف العربية. تعلم تحسين (Tahsin)

تحسين هو العلم في دراسـة الأصيوات العربية. تطبق فقط على اللغة العربية, ولاينطبق على اللغة الأخرى. تحسين هو العلم الذي يتعلم كيف تنطق الأصهوات العربية. من خلال تعلم تحسين, يمكن للمتكلمين معرفة طريقة النطق الأصيوات العربية الصحيحة. كما يتم تدريب المتكلمين على التحدث باللغة العربية بفصاحة.

\section{الخاتمة}

استنادا إلى نتائج المقارنة بين أصهوات اللغة العربية واللغة الجاوية, يمكن الاستدلال علي ان فونيمات الأصوات الصائتة تستند إلى ارتفاع اللسان ، والانتقال إلى الوراء في اللسان ، 
وهيكل الفم وشكله. وفي حين ان أصوات الصائتةعلي أسـاس مكان عملية النطق ، وطريقة التعبير ، وما إذا كان أو لايهتز الحبل الصوتية. ويمكن تلخيصها علي ذلك: ( ) الأصهوات الصائتة والأصيوات الصامتة في اللغة العربية والجاوية.

أ) هناك ستة أحرف الصوائت باللغة العربية التي تنقسم إلى أصوات الصيائتة القصيرة أصوات الصائتة الطويلة. تتكون أصوات الصائتة القصيرة من /a/, /i/, /uتكون

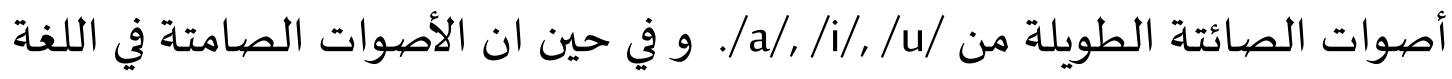
العربية تتكون من ^ץ حرفا وهي: ا, ب, ت, ث, ج, ح, خ, د, ذ, راز, س, ش, ص, ض, ط, ظ, ع,غ, ف, ق, ك, ل, م, ن, و, هري. ب) هناك ستة أحرف الصوائت باللغة الجاوية وهي /o/,/a/,/i/,/u/,/e/, /. و في حين /b/,/c/,/d/,/f/,/g/, ان الأصوات الصامتة في اللغة العربية تتكون من اب حرفاوهي /h/,/j/,/k/,/l/,/m/,/n/,/p/,/q/,/r/,/s/,/t/,/v/,/w/,/x/,/y/,/z/ r) المعادلة والفرق على الأصيوات الصائتة الأصيوات الصامتة في اللغة العبية والجاوية. أ) المعادلة على الأصيوات الصيائتة الأصهوات الصيامتة في اللغة العربية والجاوية هناك المعادلات من أصوات الصائتة في اللغة العربية والجاوية. هناك أصهوات الصائتة /a/, / / / في العربية و حتى مع اللغة جاوية. 
هناك المعادلات من أصوات الصامتة في اللغة العربية والجاوياة. هناك أصهوات الصائتة ,b/,/d/,,g/,/h/,/j/,/k/,/l/,/m/,,/n/,,q/,/r/,,s/,/t/,/v/,/w/,/y/

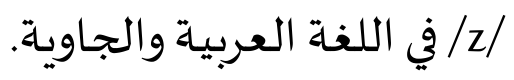

ب) الفرق على الأصيوات الصائتة الأصوات الصامتة في اللغة العربية والجاوية

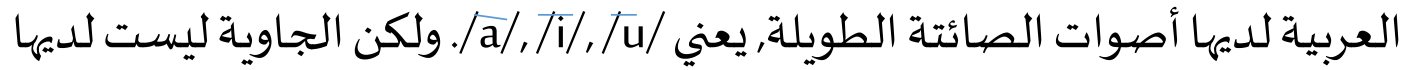
أصوات الصائتة الطويلة.

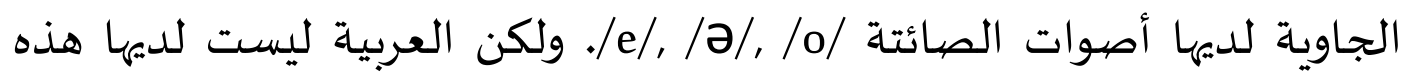
الصوائت. العربية لديها أنصاف الحركات ولكن الجاوية ليست لديها أنصاف الحركات

محمد علي الخول ,معجم علم الأصيوات, رياض :جامعة الرياض, ب191 أحمد مختر عمر ,الدرسات الصيوت اللغوي, قاهرة :ألم الكتوب, 1991 ابد الله ربي محمود, وأصدقائه, علم الصوتيات, مكة المكرمة :مكتبة الطالب الجمع , 1911 دافد أبير كيرمب ,مابدي علم الأصيوات العام ,ترجمة محمد الفاتة, قاهرة : 1911 كمال إبراهيم بدري, علم اللغة البرمجِ, الرياض: جامعة الملك سعود, ع ا ـr 
M. Echols, John dan Sadily, Hasan, Kamus Inggris-Indonesia, Jakarta: PT Gramedia, 1998 Henry Guntur Tarigan, Pengajaran Analisis Kontrastif Bahasa, Ed. Revisi, Bandung: Angkasa, 2009

Pranowo, Analisis Pengajaran Bahasa, Yogyakarta: Gajah Mada University Press, 1996 Jos Daniel Parera, Linguistik Edukasional: Pendekatan, Konsep, dan Teori Pengajaran Bahasa, Jakarta: Erlangga, 1987

Henry Guntur Tarigan, Pengajaran Remedi Bahasa, Bandung: Angkasa, 2009

Haerika Febrianawati, Analisis Kontrastif Kalimat Aktif-Pasif dalam Bahasa Arab dan Bahasa Jepang, Skripsi, Jurusan Pendidikan Bahasa Arab Fakultas Ilmu Tarbiyah dan Keguruan UIN Sunan Kalijaga Yogyakarta, 2013

I Wayan Jenda, Dasar-Dasar Sosiolinguistik, Denpasar: Ikayana, 1991

Mansoer H. Padeta, Pengantar Fonologi, Gorontalo: Viladan, 2003

Anton M. Moeliono, Pengembangan dan Pembinaan Bahasa, Jakarta : Djambatan, 1981

Abdul Chaer, Fonologi Bahasa Indonesia, Jakarta: PT. Rineka Cipta, 2009

Kurnia, Linguistik Umum, Palembang: 2013

J.W.M. Verhaar, Asas-Asas Linguistik Umum, Yogyakarta : Gajah Mada, 2010

Marsono, Fonetik, Yogyakarta: Gajah Mada University Press, 2013

Ahmad Sayuti Anshari Nasution, Bunyi Bahasa, Jakarta: UIN Jakarta Press, 2006, Cet I

Sry Satriya Tjatur Wisnu Sasangka, Bunyi-Bunyi Distingtif Bahasa Jawa, Yogyakarta: Elmatera Publishing, 2011

Balai Bahasa Yogyakarta, Kamus Bahasa Jawa (Bausastra Jawa), Yogyakarta: Kanisius, 2000

Mardalis, Metode Penelitian: Suatu Pendekatan Proposal, Jakarta: Bumi Aksara, 2008

Tatang M. Arifin, Menyusun Rencana Penelitian, Jakarta: Rajawali, 1986, Cet. Ke-1

Andi Prastowo, Memahami Metode-Metode Penelitian Suatu Tinjauan Teoritis dan Praktis, Yogyakarta: Ar-Ruzz Media, 2011

Sunarno Wirakhmad, Pengantar Penelitian Ilmiah: Metode, Dasar, dan Teknik, Bandung: Tarsito, 1994 